HIGH BLOOD LACTATE LEVEL AND LOW O2 EXTRACTION RATIO AS A MARKER OF LIVER RETRANSPLANTATION

P.F. Laterre, G. Hanique, Th. Dugernier, M. Andresen, A. Dougnac, J. Roeseler, M.S. Reynaert

Early graft dysfunction after liver transplantation (OLT) is often difficult to assess when only based on liver enzymes levels and bile production. High lactate level was evaluated as a marker of poor graft function. In 29 pts undergoing OLT simultaneous measurement (mes) of blood lactate levels, $\mathrm{mVO} 2$ (indirect calorimetry-Deltatrac ${ }^{R}$, Datex), DO2 (thermodilution) and $\mathrm{O} 2$ extraction ratio $(\mathrm{EO} 2 \mathrm{r})$ were performed within the first 48 postoperative hours. The pts were divided in 3 groups (G) according to their clinical evolution. GI (19 pts-28mes) : no postoperative hemorrhage (H), good graft function (GF) ; GII (5pts-8mes) : acute postoperative H, GF ; GIII (5pts-9mes); no $\mathrm{H}, \mathrm{G}$ dysfunction and early retransplantation (RT). Mean values of $\mathrm{VO} 2$, $\mathrm{DO} 2$, EO2r and lactates (L) are reported on the Table.

\begin{tabular}{|l|c|c|c|c|c|}
\hline & $\mathrm{n}$ mes & $\begin{array}{c}\mathrm{VO} 2 \\
\mathrm{ml} / \mathrm{min} / \mathrm{m}^{2}\end{array}$ & $\begin{array}{c}\mathrm{DO} 2 \\
\mathrm{ml} / \mathrm{min} / \mathrm{m}^{2}\end{array}$ & $\begin{array}{c}\mathrm{EO} 2 \mathrm{r} \\
\%\end{array}$ & $\begin{array}{c}\mathrm{L} \\
\mathrm{mmol} / \mathrm{L}\end{array}$ \\
\hline GI & 28 & 152 & 783 & 20 & 1 \\
\hline GII & 8 & 158 & $596^{\star}$ & $28.3^{*}$ & $2.21^{*}$ \\
\hline GIII & 9 & 158 & $759^{\circ}$ & $21.2^{\circ}$ & $3.29^{\circ}$ \\
\hline
\end{tabular}

- GI compared to GII ; ${ }^{\circ}$ GII compared to GIII ; p<0.05.

In GII high $\mathrm{L}$ levels with elevated EO2r indicates a relative tissue hypoxia due to reduced DO2 secondary to hemorrhage. In GIII, high L levels with EO2 $r<25 \%$ indicates graft dysfunction.

Conclusion : Simultaneous low EO2r $(<25 \%)$ and high L ( $>2 \mathrm{mmol} / \mathrm{L})$ when present after the first $\mathbf{4 8}$ postoperative hours are specific and early markers of graft dysfunction. Normalization of EO2 (adequate DO2) is necessary to avoid the influence of tissue hypoxia on $L$ levels. Residual hyperlactacidemia could be an early indication of retransplantation.

Department of Intensive Care, University of Louvain Medical School, Brussels, Belgium.

\section{Organization and management I}

\section{7}

THE USE OF TECHNOLOGY IN DEFINING CASE-MIX IN INTENSIVE CARE UNITS; RESULTS FROM A MULTI-CENTAE STUDY

F.G. Hulsebos, F.W. Bettrnan, D. Feis Miranda*

From February through July 1990 data were pooled from 36 Dutch ICUs to evaluate their performance and cost-effectiveness. From each patient admitted in this period physiologic formance and cost-effectiveness. From each patient admitted in this period physiologic parameters were registered together with a daily TIS.
11.665 patients and more than 37.000 patient-days.

11.665 patients and more than 37.000 patient-days. This study reports on the ongoing research at our division on how patient characteristics, other
than severity of illness, age, etc. can contribute to the development of a simplified case-mix than severity of illness, age, etc. can contrist

scoring system on admission on the ICU.
An analysis was done on 8703 patients to identify a relationship botwoen technology used on An analysis was done on 8703 patients to identify a relationship betwoen technology used on the day of admission and outcome (mortality), workload during the admission period (TISS) and

Groups were formed based upon the used technology. Group If: mechanical ventilation, group III: Phimonary artery catheter; group N: the use of more than one vaso-active drug. Patients who (MORT = mortality on the ICU, SURG $=$ the percentage of surgical patients).

\begin{tabular}{|c|c|c|c|c|c|c|c|}
\hline \multicolumn{8}{|c|}{ Characteristics of technology-based groups $(n=8703)$} \\
\hline & I & ॥ & III & $\mathrm{N}$ & $\|+\| I$ & $\|+N$ & $I I+I I++1 V$ \\
\hline (n) & 5951 & 1210 & 179 & 232 & 232 & 286 & 485 \\
\hline APACHE & $9.8 \pm 6.0$ & $12.8+7.2$ & $12.4 \pm 6.7$ & $15.3 \pm 7.2$ & $13.5 \pm 6.1$ & $17.5 \pm 8.6$ & $14.5 \pm 6.5$ \\
\hline TISS & $15.6 \pm 6.7$ & $28.8 \pm 7.1$ & $29.3 \pm 7.2$ & $22.3 \pm 7.0$ & $40.5 \pm 6.4$ & $34.6 \pm 7.0$ & $45.2 \pm 6.5$ \\
\hline LOS & $2.2 \pm 4.1$ & $5.7 \pm 9.5$ & $3.1 \pm 4.4$ & $2.7 \pm 3.5$ & $6.6 \pm 10.5$ & $5.6 \pm 10.3$ & $4.4 \pm 8.3$ \\
\hline AGE & $60.9 \pm 17.8$ & $58.1 \pm 17.4$ & $63.5 \pm 14.3$ & $68.6 \pm 14.4$ & $63.8 \pm 13.2$ & $63.9 \pm 17.0$ & $63.7 \pm 11.6$ \\
\hline MORT. & $3.7 \%$ & $13.1 \%$ & $10.1 \%$ & $18.5 \%$ & $12.9 \%$ & $32.2 \%$ & $15.9 \%$ \\
\hline SURG. & $51 \%$ & $67 \%$ & $56 \%$ & $32 \%$ & $80 \%$ & $53 \%$ & $85 \%$ \\
\hline
\end{tabular}

Mean age was, unlike the other variables, not significantly different between groups.

Group I $(n=5951)$, representing $65 \%$ of the admitted patients had the lowest mortality rate $(3.7 \%)$, mean APACHEII-score $(9.8 \pm 6.0)$ and mean TISS-score $(15.6 \pm 6.7)$. The highest mortaitiy was found in group II+N (32.2\%). The lower mortality (15.9\%) observed in the group of patients utilizing all three technologies $(1 i+1)+M$ can be explained by the high percentage coronary artery bypass surgical patients $(58 \%)$ compared to group $11+$ III $(\mathbf{8 \%})$.

The same analysis was done concerning these technologies used during the whole admission. The results from this second analysis were not difterent from those presented above. In other words, the technology used on the day of admission was representative for the whole length of stay.

It can be concluded that there is a strong relationship between the used technology on the day of admission on the ICU and APACHEII, TISS, LOS and mortality

The use of technology on admission may contribute to identifying case-mix categories. providing better insight into the cost-effectiveness analysis of ICUs.

* Intensive Care Division, Dept. of Surgeny, University Hospital, P.O. Box 30.001, 9700 RB Groningen, The Netherlands
PASSIVE STRETCHING EFFECTS THE WASTING OF MUSCLE IN THE CRITICALLY-ILL

RD Griffiths, PA Maclennan, T Helliwell, RR Macmillan.

This study examines whether the muscle wasting in the catabolic intensive care patient can be prevented by passive stretching alone in the absence of any contractile activity. Five critically ill patients ( $2 \mathrm{~F}: 3 \mathrm{M}$, ages $28-61$ ) who required complete neuromuscular blockade for seven days of ventilator support were studied. On each patient one leg was placed in a "Straumann" lower limb continuous passive motion (CPM) unit for three 3 hour periods per day to produce about $25 \%$ functional stretch of the anterior tibialis muscle at 10 cycles per minute. Percutaneous muscle biopsies were taken from both limbs at the start and after seven days.

Results: Prevention of fibre atrophy could be seen in the more severely ill patienis (admission APACHE scores 19, 21, 22) with a slight gain in fibre area, mean $+15 \%$ $(-10 \%$ to $+27 \%)$ in the CPM limb compared with the control leg which decreased by a mean $-36 \%(-32 \%$ to $-42 \%)$ over seven days $(p=0.027, n=3)$. Changes in fibre size were not significant in the less severely ill patients (APACHE $=11 \& 13$ ). The preservation of fibre area was seen in both fibre types but was more pronounced in type 1 muscle fibres (CPM $+8 \%$, control $-36 \%, p=0.02, n=3$ ). There was no change in the proportion of type 1 fibres (mean 75\%). Oualitative changes were varied but apparent between the two limbs. In one patient type 2 fibre atrophy in the CPM limb matched the increase in type 1 fibre area. In one of the patients in renal failure passive motion prevented the development of marked atrophy and necrosis seen in the control limb. The loss of protein ( $\mathrm{g} \%$ wet $\mathrm{wt}$ ) was significantly less in the CPM limb $-2.7 \mathrm{~g} \% \mathrm{v}$ control $-5.4 \mathrm{~g} \%,(\mathrm{n}=5, \mathrm{p}=0.004)$. There was a significantly greater increase in the wet wt per mg DNA in the control limb $(33 \%$ v $10 \%, p=0.03, n=5)$. However, as an index of wasting, the protein/DNA ratio decreased similarly in both limbs (CPM $-8.4 \%$ v control $-12.1 \%, n=5, N . S$.). There was no change in the RNA/protein ratio which suggests that the protein synthetic capacity was unaltered. Conclusion: Passive stretching can preserve the architecture of muscle fibres Whether it can prevent muscle protein loss remains uncertain. In the critically-ill the presence of oedema, necrotic, de/regenerating fibres and leukocytes confuse the interpretation of the biochemical markers of wasting. Protein synthesis could be masked by a stimulation of satellite cells increasing DNA in the CPM limb. or conversely these changes may be due to a reduction in tissue oedema.

Departments of Medicine \& Pathology, University of Liverpool. L69 3BX \& The Intensive Care Unit, Whiston Hospital, L35 5DR, UK

\section{8}

MONITORING THE CORRESPONDENCE BETWEEN RESOURCE UTILIZATION AND SEVERITY WHEN SEVERITY IS MAXIMUM Ruiz, J."; Garcia, L. ; Gonzalez, Y.*; Boix, A.*, $\frac{\text { Ruiz, J.'. Garcia, L.; Gonzallez, Y. ; Boix, A."; }}{\text { Asenjo, M.A.* }}$ The purpose of this study was to investigate the
correspondence between resource consumption, as
indicated by TISS (Keene R. and Cullen D.J., C.C.M. indicated by TISS (Keene $R$, and Cullen D.J.' C.C.M.,
January 1983; 11, $1: 1-3$ ), and severity, as indicated bY January 1983; 11, 1:1-3), and severity, as indicated by when severity was maximum. 'Consecutive and prospective determinations of SAPS and TISS were made on a daily basis during a period of 20 months for a total of 541 patients.

At weekends the ICU is attended only by physicians - on - call, hence an analysis was also done to see if there were done to see if there were correspondence depending correspondence depending on the variable weekend / statistical test was used to measure the difference ( $p$ 0.05 ). DBase III plus and SPSS 3.0 . ooftware were uging.
The study was performed in the medical gurgical ICU of a general hospital.

RESULTS

coincidence....................75.608

Non coincidence..................6.658

Max TISS the day before max.SAPS.......13.318

Max TISS the day after max. SAPS....... 4.448

8 of coincidence in regard to weekends (115 cases): During week days $\ldots \ldots \ldots \ldots \ldots \ldots, 70.4{ }^{8}\left(x^{2}=2.28 ; p=0.1312\right)$ During weekends $\ldots \ldots \ldots \ldots \ldots \ldots$ 77.28 $\left(x^{2}=2.28 ; p=0.1312\right)$ DISCUSSION: If greater resource utilization is significantly related to greater severity. TISS could be
used to monitor the correspondence of resource used to monitor the correspondence of resource used to monitor intrinsic quality. Rather than indicating a "failure" of TISS to respond adequately to severity variations, the 25 deviation found in this study is the result of inappropriate utilization of resources; though, at lest, this phenomenon was not found to increase significantly at weekends.

U.c.I., Hospital Central, Q.S. Alianza. Padre claret 135. 08025 - Barcelona, Sp. ** Hospital Cruz Roja, Barcelona *** Facultad de Medicina, Univ. de Barcelona 
129

MAMAGEMENT OF ICUS. A SIMPLIFIED INOEX TO ASSESS THE RURSE HORKLOAD : icuPRM

F Saulnier, J.M. Descamps, G. De Pouvourville, A. Durocher, B.

Blettery, J. Carlet, F. Fraisse, F. Nicolas, Ph. Lardet, H. Hubert, S. Loyez, D. Sion.

An appropriate number of nurses to achieve required care is essential to develop quality of care in ICUs. The PRN system, developed in Canada, is based on the daily collection of 249 parameters speaded over 118 nursing acts classified in 8 groups. Each PRN point requires 5 minutes of work. This system is specific, but too time consuming to be routinely collected. A multicentric study (25 ICUs, 735 patients) collected daily detailed PRN data from admission to discharge. A simplified index (icuPRN) has been elaborated : 35 nursing acts were selected and weighted by using a principal components analys is and a multiple regression analys is. The aim of this study was to validate icuPRN among another sample of ICUs patients.

Methods : Both indexes, PRN and icuPRN, were prospectively recorded for each patient every day in 6 ICUs. Nurses did not know the values of icuPRN acts. The indexes were compared with a linear regression and agreement was evaluated by the Bland and Altman method.

Results : 141 consecutive patients were studied : mean age $57 \pm 17,5$

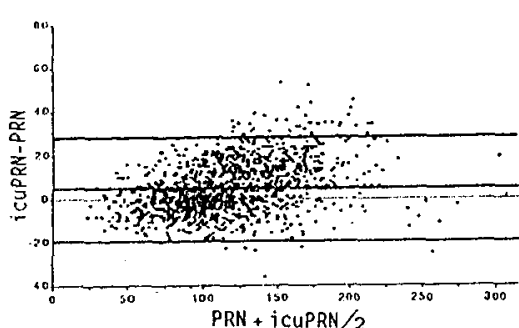

years : length of stay $9 \pm 9,6$ days : SAPS 13*5.9. Daily PRN $(113+37,4)$ and icuPRN $(117+42,4)$ were strongly correlated $\quad(r=0,96$. $p<0,0001 ; 1388$ days). The average difference between data pairs (icuPRN-PRN) was $4 \pm 11,9$ The plot of the bias and ean values shows that nearly all data point

i> 97\%) fall within the $95 \%$ confidence interval ( $+2 S D$ of the bias). Conclusion : The icupRN provides an accurate assessment of the nurse workload in ICU. This index is simpler than the PRN system and could be routinely used.

Medical Evaluation Institute. Medecine Faculty, 59045 Lille.France.

\section{1}

COMPARISON OF QUALITY OF LIFE SIX MONTHS AFTER ICU WITH A STRATIFIED RAN. DOM SAMPLE OF A DUTCH POPULATION

F.W. Beltman, R.G. Hulsebos, D. Reis Miranda"

Assessment of 'quality of life' is important for determining outcome of ICU-patients. Oppo site to mortality, 'quality of life' is dependent on social standards. During six months of 1990, 36 ICU's participated in a multidisciplinary study to ovaluate their porformance an cost-effactiveness. Six months after discharge from ICU all patients who were still alivo received the Sickness Impact Profile (SIP); recovery patients ware excluded. This study reports the comparison of 'quality of life' after ICU with a stratified random sample of Dutch population $(n=594)^{2}$. SIP was used colf-admiristered in both populations in agegroup 18-75 years. ICU-rosults concern 3146 patients; $57.3 \pm 14.2$ yoars of $890,65 \%$ men, $32 \%$ medical and $68 \%$ surgical $(22 \%$ unscheduled, $78 \%$ scheduled) with mean severity of iliness (APACHE II) of $9.5 \pm 5.0$ and length of stay of $2.7 \pm 4.4$ days. Mean SIP-score was $7.8 \pm 8.9$ (min. 0 , max. 60.5). Females scored higher than malos $(8.9 \pm$ 9.8 vs. $7.3 \pm 8.3 ; p=0.00)$ while mean age was lower $(55.8 \pm 16.0$ vs. $58.0 \pm 13.2$ $p=0.00$ ). Mean SIP-score in the open population was 3.4 (female 3 .

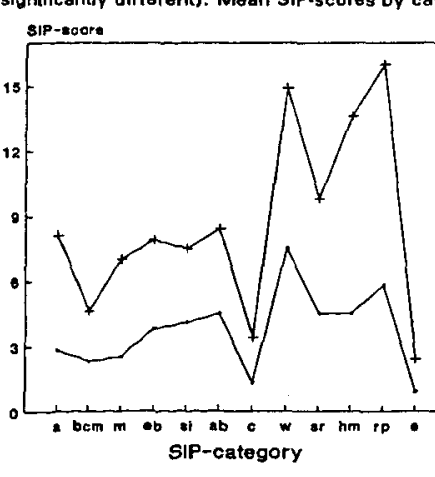

(a: ambulation, bem: body cara and move ment, m: mobility, ob: emotional behavior. si: social intoraction, ab: alertness behovior, c: communication, w: work, sr: sleep and rest, hm: housohold management, rp: recreation and pastimes, o: eating) ICU-pationts have higher scores in all categories but curves have the same characteristics. Howover differences aro small in bem, $c$ and $o$; largost in w, hm and ip. In the open population dysfunction in $8 \mathrm{t}$ $\mathrm{hm}$ and physical dimension $(a, b c m, m$ ) risos with increasing ago. in the ICU-population this rolation does not oxist. Overall corrolation betwoen age and SIP $0.03(0=0.045)$. and $41-50$ yoars havo hioups of $31-40$ and 41-50 yoars havo highost psychosocial dimension (si, ab, ab, c) scores in both studies. Scores of pationts with nonspecific abdominal complaints and pationts in

- Open population + ICU population the loast sovere class of rheuma are com-
perable with ICU-pationts.

- Open population + ICU population the loast sovere class of rheuma are com-
perable with ICU-pationts. Conclusions: ICU-patients showed minor to medium behavioral dysfunction. Type of $a g \theta$ and sexo is difforont.

"Department of Surgery - University Hospital Groningen, Oostersingel 59, 9700 RB Groningen " Jacobs ot al., The 'sickness impect profila': rosults of a validation study of the Dutch version (summery in English). Ned Tijdschr Genooskd 1990; 134: 1950-54
130

WITHDRAWAL OF LIFE SUPPORT:. THE DEVELOPMENT AND EVALUATION OF A QUESTIONNAIRE. DJ COOK.

The decision to withdraw life support is one of the most difficult to face the intensive care unit (ICU) physician. A questionnaire was developed and tested to determine the factors which influence the decision to withdraw life support amongst ICU health care providers.

Sixteen realistic scenarios describing difficult decisions regarding withdrawal of life support were developed on the basis of discussion with ICU attendings, housestaff, nurses and a review of the literature. The questionnaire was administered to $5 \mathrm{ICU}$ attendings, $5 \mathrm{ICU}$ housestaff and 5 ICU nurses. Two scenarios were administered to each respondent. Realism of the scenarios and clarity of the questions were confirmed.

Clinical sensibility of the questionnaire was evaluated by 28 methodologists and health care providers. $87 \%$ of respondents felt that the questionnaire was directed at important elements in the decision making process and $74 \%$ felt the questionnaire was likely to elicit candid information.

Reliability was tested by administering the same questionnaire to 25 ICU health care workers 2 weeks apart. For items that were not highly skewed (religious affiliation, sexual orientation, and gender of the patient), the intraclass correlations ranged from 0.68 to 0.96 .

A clinically sensible, reliable method of measuring the factors and attitudes that influence the decision to withdraw life support has been developed. This questionnaire may be useful to researchers, educators, ethicists and intensivists.

Departments of Medicine, Clinical Epidemiology \& Biostatistics, McMaster Unjversity Faculty of Health Sciences, 1200 Main St. West Hamilton, Canada L8N 375

\section{2}

PREVALENCE OF MECHANICAL VENTILATION IN INTENSIVE CARE UNITS (ICU'S). SPANISH MULTICENTER STUDY.

Spanish collaborative group for the study of respiratory failure.

BACKGROUND : Mechanical ventilation (MV) is one of the most common therapeutic interventions in ICU's. However, few studies have investigated the number of critically ill patients on MV at a particular time and the ventilatory modes most commonly used.

OBJETIVE : To investigate the number of patients that are admitted to general ICU's and are on MV, and the ventilatory modes utilized.

DESING : A descriptive multicenter study.

METHOD : Questionnaires containing information pertaining to demographic data indication for ICU admission, indication for MV, and ventilatory mode used, were sent to the different ICU's participant in the study. The survey was repeated 6 months later.

SETTING : 52 spanish ICU's participated in the study. $72 \%$ were ICU's from $100-400$ bed hospitals, $19 \%$ from $>400$ bed hospitals, and $9 \%$ from $>1000$ bed hospitals.

PATIENTS : All patients that were on MV in 5/20/1991 (day 1) at 10.00 AM hours, and in $1 / 20 / 1992$ (day 2 ) at 10.00 AM hours.

RESULTS : 272 and 290 patients were on MV days 1 and 2, respectively $147 \%$ and $46 \%$ of all patients admitted to ICU's). Age and Apache II score (mean \pm SDM) were $51+20$ and $17 \pm 8$ on day 1 and $55+19$ and $15+8$ on day 2 The percent of patients admitted because of chronic respiratory disease increased significantly $(p<0.01$ ) from $10 \%$ to $20 \%$ between days 1 and 2 , whereas that of polytraumatized patients decreased from $30 \%$ to $19 \%$ ip $<0.0011$.. The most frequently ventilatory mode used was assist/control $162 \%$ and $55 \%$, for days 1 and 2, respectively) and IMV with or without pressure support (27\% and $34 \%$ ). Other modes such as pressure support, pressure controlled ventilation and CPAP were used less often. No PEEP was used in $43 \%$ of patients on day 1 , and in $46 \%$ on day 2 .

CONCLUSIONS : Around half of patients admitted to ICU's in our spanish multicenter study are mechanically ventilated at any given moment. Most of them are ventilated using classical ventilatory modes, such as assist/control and IMV whereas more moderm modes are used more sparingly at the present time.

Unidad de Cuidados Intensivos. Hospital Universiterio de Getafe. Carretera de Toledo km 12'500. 28905 Gotafe. Madrid. Spain. 